\title{
Development of shelf-life kinetic model for modified atmosphere packaging of fresh sliced mushrooms
}

\author{
F. Oliveira ${ }^{\mathrm{a}, \mathrm{b}}$, M.J. Sousa-Gallagher ${ }^{\mathrm{a}, *}$, P.V. Mahajan ${ }^{\mathrm{a}}$, J.A. Teixeira ${ }^{\mathrm{b}}$ \\ ${ }^{a}$ Department of Process \& Chemical Engineering, School of Engineering, College of Science, Engineering and Food Science, University College Cork, Ireland \\ ${ }^{\mathrm{b}}$ Institute for Biotechnology and Bioengineering (IBB), Centre of Biological Engineering, University of Minho, Braga, Portugal
}

\section{A R T I C L E I N F O}

\section{Article history:}

Received 22 June 2011

Received in revised form 17 January 2012

Accepted 26 January 2012

Available online 15 February 2012

\section{Keywords:}

Shelf-life

Modelling

Mushrooms

MAP

Micro-perforations optimal gas composition

\begin{abstract}
A B S T R A C T
Mushrooms are highly perishable and their shelf-life depends on processing, package properties and environmental conditions during storage and distribution. The aims of this work were to evaluate the effect of temperature and number of film perforations on quality and develop shelf-life kinetic model for a modified atmosphere packaging (MAP) for sliced button mushrooms. Sliced mushrooms were packed in a tray, covered with cellophane film, and stored for 7 days at four levels of temperature $(0$, 5,10 , and $15^{\circ} \mathrm{C}$ ) and three levels of perforations at each temperature ranging the number of perforations from 1 ( 58 perforations per $\mathrm{m}^{2}$ ) to 6 (349 perforations per $\mathrm{m}^{2}$ ). Headspace gas composition and quality parameters (weight loss, $\mathrm{pH}$, firmness and colour) were measured throughout the storage period. Increasing the storage temperature required an increase of the number of perforations in order to obtain the optimum MAP conditions. Temperature had a significant effect $(p<0.05)$ on quality of sliced mushrooms. Firmness was identified as a critical quality parameter; therefore, a kinetic model was developed to describe the influence of temperature on firmness and predict shelf-life of sliced mushrooms. Fresh sliced mushrooms had a shelf-life of $1,2,4$, and 7.5 days at $15,10,5$, and $0{ }^{\circ} \mathrm{C}$, respectively, under optimum MAP conditions.
\end{abstract}

(c) 2012 Elsevier Ltd. All rights reserved.

\section{Introduction}

Mushrooms are highly perishable and their shelf-life is 13 days at ambient temperature, due to high moisture content and high transpiration rate (Mahajan et al., 2008). Therefore, mushrooms need a special care to keep its quality and freshness, especially when they are minimal processed such as slicing (Iqbal et al., 2009). Mushrooms are usually marketed in trays overwraped with perforated polyvinylchloride (PVC) stretchable film (Simon et al., 2005) with little or no atmosphere modification. The use of modified atmosphere packaging (MAP) accompanied with low temperature storage can effectively retard the quality changes and extend shelf-life of fresh-cut mushrooms.

A modified atmosphere is created inside the package, depending on the respiration rate of mushroom, gas permeability of the film, amount of product, the breathable film area and storage temperature. An optimal MAP for mushrooms should be carefully designed considering respiration as a function of temperature, as well as the packaging film permeability to produce optimal gas composition in the package that can maintain initial quality and extend shelf-life of fresh mushrooms. MAP design can be

\footnotetext{
* Corresponding author.

E-mail address: m.desousagallagher@ucc.ie (M.J. Sousa-Gallagher).
}

attributed to low $\mathrm{O}_{2}$ and high $\mathrm{CO}_{2}$ concentrations in the atmosphere that surrounds the product, decreasing the respiration rate of the product and inhibiting microbial growth. Usually $\mathrm{O}_{2}$ concentrations are kept low, 1-5\%, however, $\mathrm{O}_{2}$ level should not be less than $1 \%$ to avoid anaerobic respiration as well as growth of pathogens. $\mathrm{CO}_{2}$ concentrations should be high, but in case of mushrooms, excessive $\mathrm{CO}_{2}$, higher than $12 \%$, can cause physiological injuries, such as browning (Parentelli et al., 2007).

Temperature is the most important environmental factor in the postharvest life of fresh produce, and when decreased to lower levels, causes a reduction in the biochemical reaction rates and consequently increase its shelf-life (Robertson, 2006a). In addition, MAP design can be quite challenging, since temperature dependence of the respiration and transpiration rate are different from that of the permeability of packaging films. Thus, it is difficult to maintain the desire atmosphere within the package when the surrounding temperature is not constant.

Mushrooms are very sensitive to humidity levels; they have very high transpiration rates, over $>90 \%$ of the weight at harvest is water and they lack a skin as a barrier to diffusion (Mahajan et al., 2008). When mushrooms are packaged in MAP, the low water vapour transmission rate (WVTR) of films commonly used, combined with the high transpiration rate of mushrooms, rapidly brings about saturation ( $100 \% \mathrm{RH})$ of the package atmosphere (Roy et al., 1996). These saturated in-pack RH conditions can result 
in the condensation of water on the inside surface of the film and the contained produce, favouring microbial growth and discolouration. Ares et al. (2006) and Antmann et al. (2008) used polyethylene film for packaging shiitake mushrooms. The low WVTR of polyethylene films, combined with the high transpiration rate of mushrooms, developed nearly a saturated condition in the packages which caused mushroom deterioration, discolouration and softening. Therefore, there is an urgent need for developing high water vapour permeable films for packing of mushrooms.

Micro-perforated films are an option for achieving the appropriate gaseous composition in MAP, especially for high respiring fresh-cut products (Gonzalez et al., 2008), as is the case of mushrooms. Sanz et al. (2000) reported that the degree of perforations affected final gas contents inside the packages, with a level of perforations between 2-4 holes of $1 \mathrm{~mm}$ diameter and 1-2 holes of $2 \mathrm{~mm}$ diameter for $500 \mathrm{~g}$ of strawberries in order to achieve the recommended gas composition. Oliveira et al. (2012) reported that 2 perforations of size $0.33 \mathrm{~mm}$ diameter were optimum for $110 \mathrm{~g}$ of sliced mushrooms at $10{ }^{\circ} \mathrm{C}$, yielding $3.6 \%$ of $\mathrm{O}_{2}$ and $11.5 \%$ of $\mathrm{CO}_{2}$ at equilibrium. However, number of perforations required at other temperatures were not determined, and in order to achieve the optimum $\mathrm{O}_{2}$ and $\mathrm{CO}_{2}$ window accounting the temperature variation during supply chain, perhaps higher number of perforations would be necessary.

Product shelf-life depends on its characteristics, formulation and processing, package properties, and environment conditions during storage and distribution (Robertson, 2006b). Shelf-life of fresh mushrooms is determined by product properties, such as colour $\left(L^{*}, a^{*}, b^{*}\right)$, firmness weight loss over time. Gormley (1975) proposed as limit of acceptance of $L^{*}$ of 80 for mushrooms acceptability. Changes of quality parameters of fresh produce during storage period have been quantified by mathematical models using zero and first order degradation reaction kinetics and Weibull probability distribution. Mohapatra et al. (2010) found temperature to play a significant role in controlling texture and colour degradation of mushrooms and reported a linear dependence of the final Browning index (BI) with temperature and an Arrhenius type relationship between temperature and storage time with respect to textural hardness. Weibull model has an interesting potential for describing degradation kinetics because of its flexible shape and ability to model a wide range of degradation kinetics. The model considers the scale parameter $(\alpha)$ as a reaction rate constant and the shape parameter $(\beta)$ as a behaviour index (Cunha et al., 1998). Weibull model was used to describe the changes of anthocyanins and antioxidant capacity of fresh cut-strawberries (Odriozola-Serrano et al., 2009) and antioxidants, vitamin $C$ and lycopene in fresh cut-watermelon (Oms-Oliu et al., 2009).

To maintain the quality and extend the shelf-life of fresh sliced mushrooms during the supply chain it would be required the design of an optimal MAP system considering the influence of the major environmental conditions (e.g., temperature) and evaluate the kinetics of the critical quality parameters under this packaging conditions to allow the development of a shelf life predictive model. Therefore, the aim of this study was to (i) optimised the number of perforations for MAP of sliced mushrooms at a range of temperatures $\left(0,5,10\right.$ and $\left.15^{\circ} \mathrm{C}\right)$ to which the product can be exposed during distribution chain in order to design an optimal packaging system and (ii) develop a mathematical model for prediction of shelf life of sliced mushrooms.

\section{Materials and methods}

\subsection{Experimental setup}

Button mushrooms (Agaricus bisporus) were purchased from a local supermarket (Supervalu, Cork, Ireland) on produce arrival day. Mushrooms were sliced obtaining $0.5 \mathrm{~cm}$ of thickness each piece, $110 \mathrm{~g}$ of them were placed in a tray $\left(11.1 \times 15.5 \times 3.4 \mathrm{~cm}^{3}\right)$ and covered with cellophane ${ }^{\mathrm{TM}} 335$ PS film $(23.3 \mu \mathrm{m}$ of thickness, barrier properties: $3 \mathrm{cc} \mathrm{m}^{-2} \mathrm{~d}^{-1}$ bar $^{-1}$ for $\mathrm{O}_{2}$ at $23^{\circ} \mathrm{C}$ and $900 \mathrm{~g} \mathrm{~m}^{-2} \mathrm{day}^{-1}$ for water vapour at $38^{\circ} \mathrm{C}$ ) supplied by Innovia Films (Innovia Films Ltd., Wigton, Cumbria, CA7 9BG, UK). The film was perforated with a needle of diameter $0.33 \mathrm{~mm}$. Perforations were uniformly positioned across the top of the film. A label of $10 \times 5 \mathrm{~cm}^{2}$ area was placed on the film, to simulate the labels found in the supermarket packaging. Each tray had two rubber septums in opposite sides for the headspace gas composition measurement. Septums were glued using silicone based resin. Two septums were made on the tray to see if there was any effect of position of film perforation and product load on stratification.

To define the number and size of perforations required in order to achieve an optimal gas composition inside the package, Pack-inMAP $^{\circledR}$ software (Mahajan et al., 2006, 2007, 2009) was used. The experiments were conducted in order to validate the optimum number of perforations required to achieve the optimum package atmosphere at each temperature studied (Table 1). Changes in package headspace gas composition were measured regularly using $\mathrm{O}_{2}$ and $\mathrm{CO}_{2}$ gas analyzer (PBI Dansensor, CheckMate 9900, Denmark). Once the optimal number of perforations was determined, a new experiment was performed to measure changes in quality parameters of sliced mushrooms at regular intervals during 7 days of storage and determine shelf life.

\subsection{Analysis of quality parameters}

The following quality parameters were determined daily.

\subsubsection{Weight loss}

The weight of sliced mushrooms in each package was measured using an electronic balance (Extend Startorius, ED4202S, Germany) and was determined as percentage of initial weight of mushrooms.

\subsection{2. $\mathrm{pH}$}

Sliced mushrooms (around 10 pieces from each package) were previously homogenized with a grinder and $\mathrm{pH}$ of that solution was measured using a digital pH meter (3310 Jenway, pH Meter, UK). An average of three replicates of the same solution of homogenized mushrooms from each package was calculated.

\subsubsection{Firmness}

The firmness of sliced mushrooms was measured with texture analyzer (Stable Micro System, Texture Analyser, UK) equipped with a $75 \mathrm{~mm}$ diameter probe at a test speed of $10 \mathrm{~mm} \mathrm{~s}^{-1}$ and contact force $1 \mathrm{~N}$. Sliced mushrooms were compressed by $20 \%$ of the sample height and firmness was expressed as maximum force (N). Due to the hardness of stem, this was removed from each piece, measuring only the firmness of the mushroom cap. An average of seven pieces from each package was analysed.

\subsubsection{Colour}

Visual colour of sliced mushroom was measured based on Hunter colour parameters $\left(L^{*}, a^{*}\right.$ and $\left.b^{*}\right)$ using colourimeter

Table 1

Combination of temperature and number of perforations used to optimise packaging of sliced mushrooms in a tray.

\begin{tabular}{lllllllllllllll}
\hline Factors & Levels & 10 & 10 & & & \\
\hline Temperature $\left({ }^{\circ} \mathrm{C}\right)$ & 0 & & & 5 & & & 10 & & 15 & \\
Number of perforations & 0 & 1 & 2 & 0 & 1 & 2 & 2 & 3 & 4 & 4 & 5 & 6 \\
\hline
\end{tabular}


(Minolta Chroma Meter, CR-300, Japan). Browning index (BI) as reported by Maskan (2001) was calculated using Eq. (1).

$\mathrm{BI}=\frac{100(x-0.31)}{0.17}$

where, $x=\frac{a^{*}+1.75 L^{*}}{5.645 L^{*}+a^{*}-3.012 b^{*}}$.

Total colour difference $(\Delta E)$ was determined by using the Eq. (2), as follow:

$\Delta E=\sqrt{\left(a^{*}-a_{0}^{*}\right)^{2}+\left(b^{*}-b_{0}^{*}\right)^{2}+\left(L^{*}-L_{0}^{*}\right)^{2}}$

$L_{0}^{*}, a_{0}^{*}$ and $b_{0}^{*}$ and $L^{*}, a^{*}, b^{*}$ are experimental data obtained at the beginning of storage and at a given time, respectively (Barrerio et al., 1997). An average of seven measures was used for data analysis.

\subsection{Mathematical modelling}

Weibull model as shown in Eq. (3) was used to describe kinetic degradation of quality parameters as a function of time.

$\frac{X-X_{e}}{X_{0}-X_{e}}=\exp \left[-\left[\frac{t}{\alpha}\right]\right]^{\beta}$

$X_{0}$ is the initial quality parameter, $X$ is the quality parameter at time $t, X_{e}$ is the equilibrium quality parameter, $t$ is the time (d), $\alpha$ is the scale parameter (d), and $\beta$ is the shape parameter.

$X_{e}, \alpha$ and $\beta$ were estimated by fitting Eq. (3) to the experimental data. The Arrhenius Eq. (4) was used to describe the influence of temperature on $\alpha$ or $\beta$ parameter.

$k=k_{\text {ref }} \exp \left[-\frac{E_{a}}{R_{C}}\left[\frac{1}{T}-\frac{1}{T_{\text {ref }}}\right]\right]$

$k$ is the parameter ( $\alpha$ or $\beta$ parameter), $k_{\text {ref }}$ is the frequency factor for $\alpha$ or $\beta$ at the reference temperature, $E_{a}$ is the activation energy $\left(\mathrm{kJ} \mathrm{mol}{ }^{-1}\right), R_{c}$ is the gas constant $\left(0.008314 \mathrm{~kJ} \mathrm{~mol}^{-1} \mathrm{~K}^{-1}\right), T$ is the temperature $(\mathrm{K})$ and $T_{r e f}$ is the reference temperature, $283.15 \mathrm{~K}$.

\subsection{Analysis of experimental data}

Statistical analysis was carried out to find effects $(p<0.05)$ of time and temperature on quality parameters by using the ANOVA tool from Microsoft Excel 2007. The estimation of models parameters was performed by minimization of the sum of squares of residuals (SSR), by using Solver tool from Microsoft Excel 2007 and the fitting was evaluated using the coefficient of determination $\left(R^{2}\right)$.

\section{Results and discussion}

\subsection{Optimisation of number of perforations}

In order to study quality of sliced mushrooms under optimal MAP conditions, number of perforations was evaluated at each temperature studied. Changes in gas composition within the packages at different temperatures and number of perforations are shown in Fig. 1. Increasing the number of perforations, $\mathrm{O}_{2}$ concentration increased within the package and $\mathrm{CO}_{2}$ concentration decreased until an equilibrium was reached within 2 days of storage. Higher temperature required more number of perforations in order to maintain equivalent gas composition. This might be due to an increase in respiration rate with temperature thereby faster gas exchange inside the package. Varoquaux et al. (1999) assessed that respiration rate of whole mushrooms at $1^{\circ} \mathrm{C}$ remained constant for 4 days; however, when stored at $10^{\circ} \mathrm{C}$, the respiration rate increased with time. Iqbal et al. (2009) also observed an increase in respiration rate with time and temperature and reported that slic- ing of mushrooms ( $8 \mathrm{~mm}$ of thickness) led to an increase of the respiration rate by $30 \%$ at $0{ }^{\circ} \mathrm{C}$ and $40 \%$ at $20{ }^{\circ} \mathrm{C}$, as compared to whole mushrooms.

Sliced mushrooms have a short shelf-life, therefore package gas atmosphere and quality evaluation was determined up to 3 days of storage, for optimising the package design at the different temperatures studied. Recommended MAP conditions for mushrooms were $3-5 \%$ of $\mathrm{O}_{2}$ and less than $12 \%$ of $\mathrm{CO}_{2}$ (Ares et al., 2006; Parentelli et al., 2007). Therefore, in order to keep the package gas composition within the recommended range, the optimum number of perforations was found to be $1,1,3$ and 6 at $0,5,10$ and $15{ }^{\circ} \mathrm{C}$, respectively. Their respective perforation density (perforations per $\mathrm{m}^{2}$ ) was $58,58,174$ and 349 . The exponential increase in number of perforations with temperature shows that temperature has a higher influence on respiration rate of mushroom than permeability of the film used. At $0{ }^{\circ} \mathrm{C}$, at least one perforation was required to avoid anoxia (insufficient $\mathrm{O}_{2}$ for aerobic respiration) and hence possibility of anaerobic microorganisms growth such as Clostridium botulinum. It showed that the needle diameter used $(0.33 \mathrm{~mm})$ was too big to use at lower temperatures, therefore smaller needle diameter which might yield gas composition close to the optimal range is recommended. It was also observed that mushrooms did not freeze at $0{ }^{\circ} \mathrm{C}$ because the freezing point of mushrooms is $-1.53{ }^{\circ} \mathrm{C}$, as reported by Mahajan et al. (2008). The number of perforations was selected in order to maintain an $\mathrm{O}_{2}$ concentration higher than $3 \%$ over time, avoiding anaerobic respiration and production of fermentative products. Regarding the package $\mathrm{CO}_{2}$ concentration, the levels obtained were slightly above $12 \%$ in packages stored at 10 and $15^{\circ} \mathrm{C}$. Oliveira et al. (2012) recommended 2 perforations, but 3 perforations would be ideal for packaging of sliced-mushrooms at $10^{\circ} \mathrm{C}$, in order to avoid exceeding the recommended limit for $\mathrm{CO}_{2}$ concentration, which potentially can cause browning of mushrooms.

\subsection{Quality evaluation of fresh sliced mushrooms}

Once the optimum MAP design conditions were selected at each temperature, a new experiment was conducted using the optimal MAP conditions ( 1 perforation ( 58 perforations per $\mathrm{m}^{2}$ ) at $0^{\circ} \mathrm{C}, 1$ (58 perforations per $\mathrm{m}^{2}$ ) at $5^{\circ} \mathrm{C}, 3\left(174\right.$ perforations per $\mathrm{m}^{2}$ ) at $10^{\circ} \mathrm{C}$ and $6\left(349\right.$ perforations per $\mathrm{m}^{2}$ ) at $15^{\circ} \mathrm{C}$ ) to study the effect of time and temperature on the quality of sliced mushrooms. The evolution of headspace $\mathrm{O}_{2}$ and $\mathrm{CO}_{2}$ composition at different temperatures is shown in Fig. 2. Equilibrium was achieved within 2 days of storage. At $0{ }^{\circ} \mathrm{C}$, the headspace $\mathrm{O}_{2}$ concentration was higher than the desired level. This is due to higher ingress of $\mathrm{O}_{2}$ in the package through a single possible perforation with the selected diameter $(0.33 \mathrm{~mm})$. It could be possible to reduce the perforation diameter in order to achieve the headspace $\mathrm{O}_{2}$ concentration within the desirable limit. At 5,10 and $15{ }^{\circ} \mathrm{C}$, the headspace $\mathrm{O}_{2}$ concentration were similar and were within the optimum range (3-5\%), between 3 and 3.5 days. Relative to headspace $\mathrm{CO}_{2}$ composition, the $\mathrm{CO}_{2}$ concentration remained below $12 \%$ at 0 and $5{ }^{\circ} \mathrm{C}$, whereas at 10 and $15{ }^{\circ} \mathrm{C}$, it exceeded the limit in 4.5 and 0.5 day, respectively. The higher $\mathrm{CO}_{2}$ concentration could cause severe browning, therefore, should be avoided (Parentelli et al., 2007).

Weight loss, $\mathrm{pH}$, firmness and colour $\left(L^{*}, a^{*}, b^{*}, \mathrm{BI}\right.$ and total colour difference) were determined once a day, at each temperature, and changes are shown in Fig. 3. Standard deviations were calculated and are represented by $y$ error bars, in the same figure. Quality parameters of sliced mushrooms were significantly affected $(p<0.05)$ by time and temperature, especially weight loss and firmness and BI. Higher temperatures contributed to higher changes, which led to high deterioration rates of quality parameters, compared to that at lower temperatures. Mohapatra et al. (2010) reported that temperature played a significant role in 

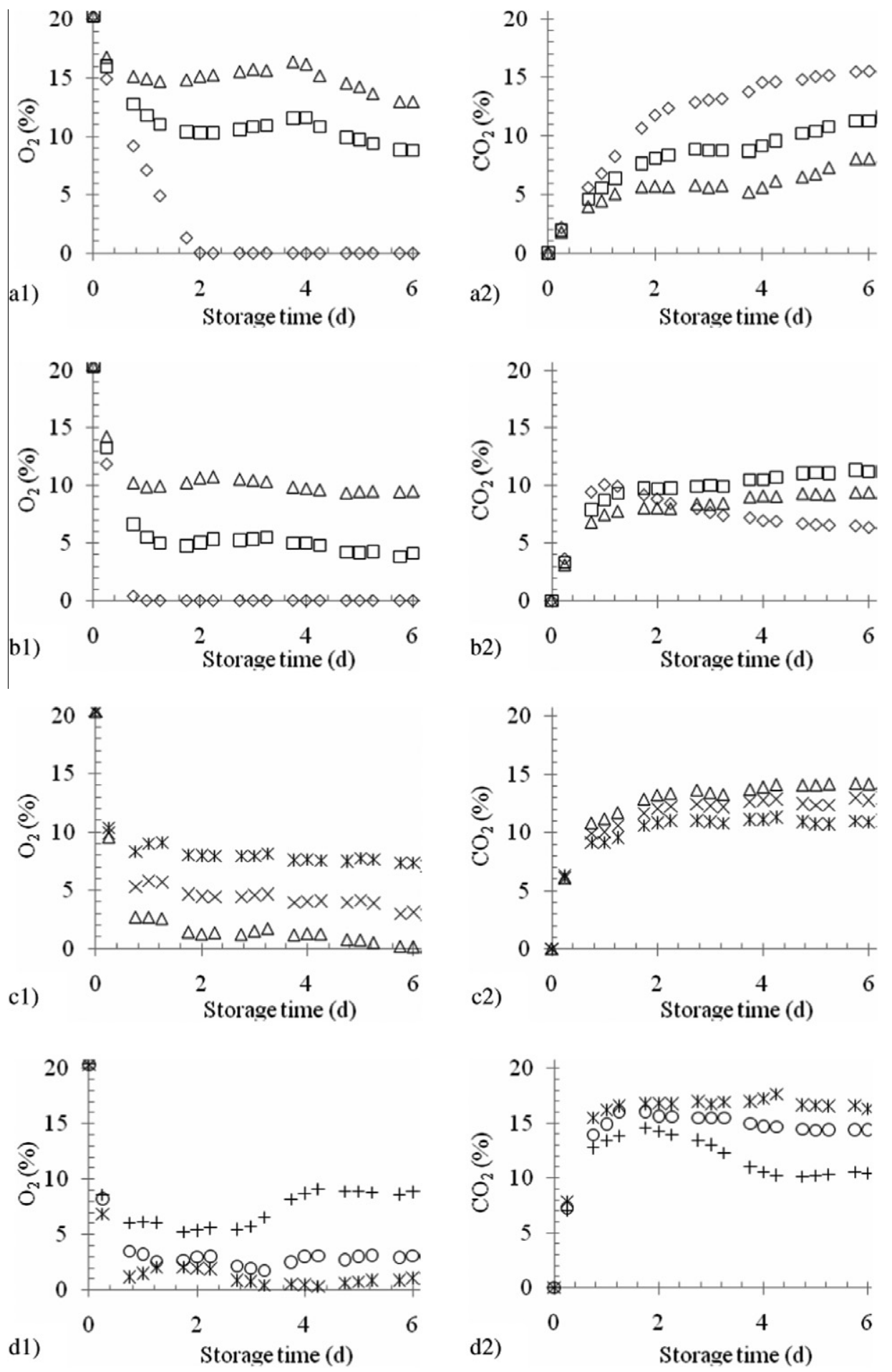

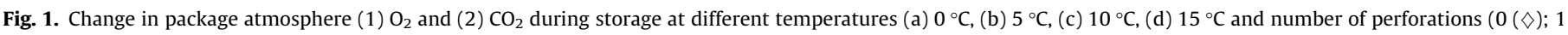
( $\square) ; 2(\triangle)$; $3(\times) ; 4(X) ; 5(\bigcirc) ; 6(+))$.

controlling texture and colour (BI) degradation and found that variation in colour of mushrooms to be less pronounced than that of texture. Escriche et al. (2001) reported that temperature influenced firmness loss more than browning of mushrooms treated with ozone, based on activation energy results.

Weight loss of sliced mushrooms increased with increase in temperature and ranged from $4.4 \%$ to $10.2 \%$ at the end of 7 days of storage. Only exception for increase in weight loss was at $0{ }^{\circ} \mathrm{C}$ which presented higher values compared to that at $5{ }^{\circ} \mathrm{C}$. This was probably due to a single perforation used which caused higher $\mathrm{O}_{2}$ (Fig. 3, a1) than recommended range and also might have caused more water loss through the perforation. Montanez et al. (2010) also observed higher gas and water vapour exchanges in the package caused by the turbulence effect created by the refrigeration fans (which run for longer period at lower temperatures) contributing for higher dehydration and consequently higher weight loss of the mushrooms. This revealed the importance of MAP design on shelf-life of mushrooms with the consideration of 

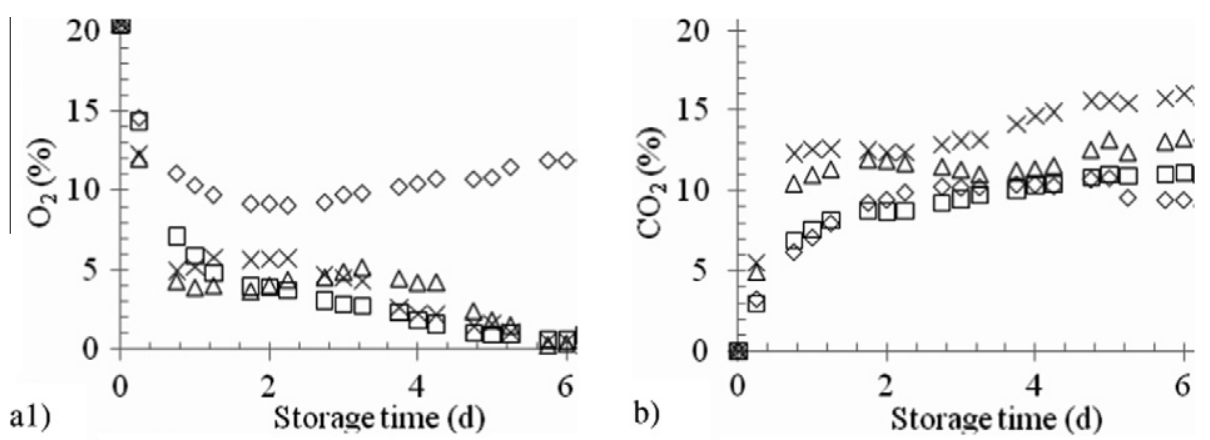

Fig. 2. Change in package atmosphere (a) $\mathrm{O}_{2}$ and (b) $\mathrm{CO}_{2}$ during storage at different temperatures $\left(0^{\circ} \mathrm{C}(\diamond) ; 5^{\circ} \mathrm{C}(\square) ; 10{ }^{\circ} \mathrm{C}(\triangle) ; 15^{\circ} \mathrm{C}(\times)\right)$.

the externals factor (temperature and air turbulence). These results meant that MAP design is important not only to control headspace $\mathrm{O}_{2}$ and $\mathrm{CO}_{2}$ composition but also weight loss, which directly affects the product quality, and may limit the shelf-life when package is not well designed. Sliced mushrooms presented a weight loss lower than $5 \%$, except for packages at $15^{\circ} \mathrm{C}$ from 3 rd day, at $10^{\circ} \mathrm{C}$ from 5 th day and at $0{ }^{\circ} \mathrm{C}$ from 6 th day. At $0{ }^{\circ} \mathrm{C}$, were not optimal, causing higher weight loss compare to that at $5^{\circ} \mathrm{C}$, which could compromise the shelf life of sliced mushrooms. These results were in agreement with Kim et al. (2006) who obtained weight loss between $3 \%$ and $5 \%$, after 6 days of storage of sliced mushrooms (5 mm thickness), in packages of polyvinyl chloride and polyolefin, at $4{ }^{\circ} \mathrm{C}$. Weight loss at $15^{\circ} \mathrm{C}$ was higher compared to that reported by Nichols and Hammond (1973), who obtained 5-7\% after 5 days, at $18^{\circ} \mathrm{C}$. Ares et al. (2006) reported whole shiitake mushrooms stored in polypropylene bag or polyethylene bag exhibited a weight loss of $5.6 \%$, after 16 days of storage, at $5{ }^{\circ} \mathrm{C}$, and mushrooms stored in polypropylene macro-perforated packages reached $47.5 \%$ after 16 days; and in polypropylene macro-perforated with lower number of perforations reached $14 \%$ after 12 days of storage. These findings confirm that weight loss is directly affected by MAP design parameters, such as WVTR of the packaging film and its perforations density, justifying the need for a film with high water vapour permeability as cellophane $\left(900 \mathrm{~g} \mathrm{~m}^{-2} \mathrm{day}^{-1}\right.$ for water vapour at $38^{\circ} \mathrm{C}$ ) for packaging of sliced mushrooms.

The $\mathrm{pH}$ was influenced by time and temperature, showing a slight decrease with both parameters. The initial $\mathrm{pH}$ of sliced mushroom was $6.74 \pm 0.01$ which decreased to $6.6 \pm 0.01$ and $6.5 \pm 0.01$ after 7 days of storage at 0 and $15^{\circ} \mathrm{C}$, respectively. Masson et al. (2002) reported an initial $\mathrm{pH}$ of 6.5 for homogenized mushroom. Aerobic mesophilic bacteria are natural contaminants in mushrooms (Zivanovic et al., 2003) which grow in presence of $\mathrm{O}_{2}$. This growth helps decreasing $\mathrm{pH}$ which ultimately inhibits the growth of certain communities. Moreover, at refrigeration temperatures the acid environment is more inhibitive, emphasizing the importance of low temperature for fresh-cut mushrooms (Heard, 2002).

The firmness of sliced mushroom decreased from an initial level of 141.4 to 95.4 and $38.9 \mathrm{~N}$ after 7 days of storage at 0 and $15^{\circ} \mathrm{C}$, respectively, representing a respective percent loss of 32.5 and 72.5. These results showed a higher decrease in firmness than that reported by Escriche et al. (2001) for whole mushrooms who observed that the firmness loss of $10 \%, 60 \%$ and $90 \%$ after 7 days of storage at 5,10 and $15{ }^{\circ} \mathrm{C}$, respectively. Loss of firmness is caused by protein and polysaccharide degradation, and loss of cell turgency due to changes in cell membrane permeability, leading to softening of mushrooms (Parentelli et al., 2007).

Colour parameter $L^{*}$ decreased with time and temperature and varied from 91.9 to 87.6 at $0{ }^{\circ} \mathrm{C}$, and to 71.9 at $15^{\circ} \mathrm{C}$; sliced mushrooms became darker with time and temperature. These results are in agreement with those reported by Escriche et al. (2001) for whole mushrooms who observed the initial $L^{*}$ of mushrooms treated with ozone was 90 , and after 7 days of storage it decreased to 80 at $5^{\circ} \mathrm{C}, 75$ at $15^{\circ} \mathrm{C}$, and 65 at $25^{\circ} \mathrm{C}$. These results were higher than those obtained by Kim et al. (2006) who observed that in different packaging materials, $L^{*}$ of whole mushrooms ranged from 76.7 to 78.8 , after 6 days at $4{ }^{\circ} \mathrm{C}$. In case of sliced mushrooms, they observed that $L^{*}$ varied from 66.8 to 78.2 , after 6 days at $4{ }^{\circ} \mathrm{C}$. $L^{*}$ parameter was in general higher than the limit of acceptance (80) proposed by Gormley (1975) confirming that colour $\left(L^{*}\right)$ was not a critical parameter in this study.

Colour parameter $a^{*}$ increased slightly $(p<0.05)$ with temperature. Initial $a^{*}$ measured was 0.08 and increased after 7 days obtaining 0.9 at $0{ }^{\circ} \mathrm{C}$ and 5.0 at $15^{\circ} \mathrm{C}$, leading to redness on sliced mushrooms at higher temperatures. Colour parameter $b^{*}$ was the most affected colour parameter $(p<0.05)$, by time and temperature. It increased from 9.88 to a range from 13.6 at $0{ }^{\circ} \mathrm{C}$ to 20.2 at $15^{\circ} \mathrm{C}$, resulting in yellowness on sliced mushrooms.

The parameter $L^{*}$ decreased and $b^{*}$ increased with time and temperature, consequently, BI increased from 11.2 to 17.3 at $0{ }^{\circ} \mathrm{C}$ and to 38.5 at $15^{\circ} \mathrm{C}$, after 7 days. Sliced mushrooms lost a luminosity and turn dark with decrease of $L^{*}$, and became yellow with increase of $b^{*}$, with time and temperature. This discoloration was induced by bruising, slicing, storage and physiological disorders and the very high polyphenol oxidase (PPO) content and phenolics compounds make them very susceptible to enzymatic browning (Mohapatra et al., 2008). Similar to BI, total colour difference $(\Delta E)$, increased with an increase in changes of individual parameters with time and temperature. Total colour difference ranged from 19.4 at $0{ }^{\circ} \mathrm{C}$, to 299.4 at $15^{\circ} \mathrm{C}$, after 7 days.

\subsection{Mathematical modelling and shelf-life prediction}

The Weibull model Eq. (3) was fitted to the changes of quality parameters (weight loss, firmness and BI) as a function of time. The estimated values of $\alpha, \beta, X_{e}$ and respective coefficients of determination $\left(R^{2}\right)$ are presented in Table 2 . In general, $\alpha$ decreased with temperature for weight loss and firmness, but increased with temperature for BI. $\beta$ was more than 1 for weight loss, firmness (at 5 and $10^{\circ} \mathrm{C}$ ) and $\mathrm{BI}\left(\right.$ at $15^{\circ} \mathrm{C}$ ), whereas it was less than 1 for firmness (at 0 and $15^{\circ} \mathrm{C}$ ) and $\mathrm{BI}$ resulting in an increase and decrease of deterioration with temperature, respectively. If $\beta<1$, there was a decreasing rate; if $\beta=1$, the rate was constant with time; and if $\beta>1$, the rate was increasing with time (Chakrabarty et al., 1998). Coefficient of determination $\left(R^{2}\right)$ showed a very good fit of model to weight loss data and suitable to firmness and BI.

The Weibull parameters ( $\alpha$ and $\beta$ ) (Table 2 ) for weight loss and firmness of sliced mushrooms followed an Arrhenius equation, whereas parameters for BI did not follow it. Mohapatra et al. (2010) found a linear dependence of temperature with the BI and an Arrhenius type relationship with textural hardness of 

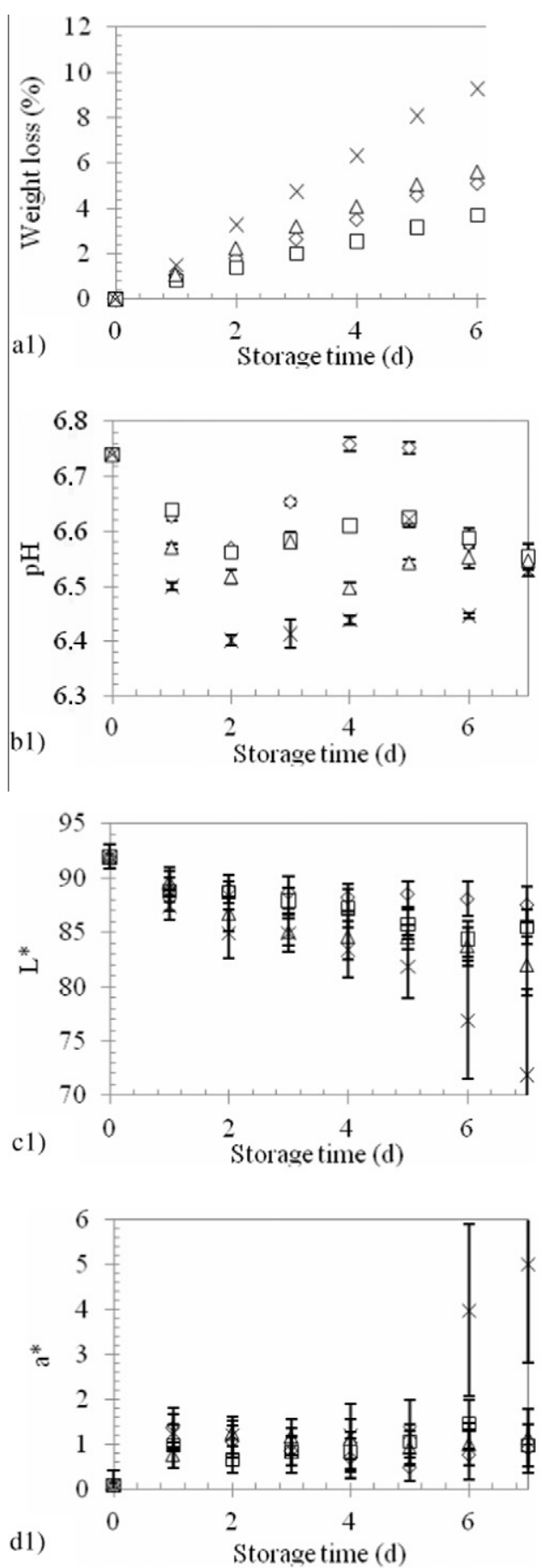
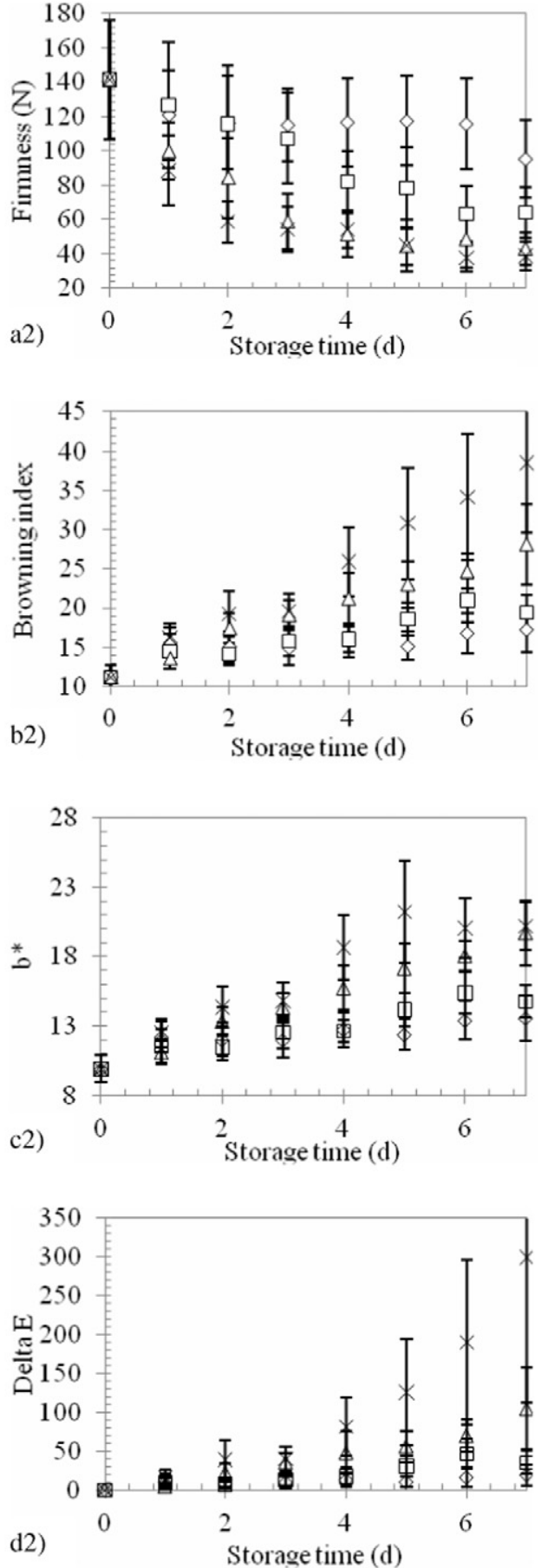

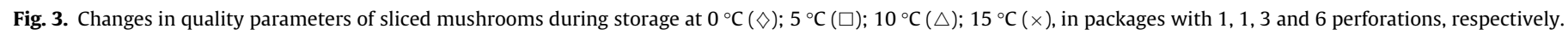

mushrooms. Coefficients of determination revealed a good fitting of the equation to firmness and a suitable fitting to the weight loss data (Table 3). The parameters $\alpha$ and $\beta$ at $0{ }^{\circ} \mathrm{C}$ were not considered for mathematical modelling for shelf life, since they did not follow the trend. Higher activation energy values indicated greater temperature sensitivity, as reported by Corzo et al. (2008). $E_{a \alpha}$ of weight loss and firmness presented higher values comparing to $E_{\alpha \beta}$ (Table $3)$. Both $E_{a \alpha}$ and $E_{a \beta}$ of firmness were higher than those for weight loss (Table 3), which meant a higher dependence of firmness on storage temperature than of weight loss, also confirmed by analysis of variance $(p<0.05)$, where it was found higher effect of temperature on firmness than on weight loss. Mohapatra et al. (2010) reported that variations in colour of mushrooms were more pronounced than that of firmness and the biggest uncertainty resided in controlling the final browning stage of the mushrooms, and that the rate of loss of hardness presented the biggest variability. It was recommended that for a temperature range $3.5-15^{\circ} \mathrm{C}$, optimisation of texture through temperature control would be more manageable than the control of browning. Therefore, firmness was identified as the critical quality parameter, since it was the parameter most affected by temperature, and also it was not influenced directly by MAP design parameters, as weight loss. Zero order equation was fitted to $X_{e}$ results of firmness (exclusion of result at $0{ }^{\circ} \mathrm{C}$ ), as a function of temperature, and the Eq. (5) was obtained. 
Table 2

Scale $(\alpha)$ and shape $(\beta)$ parameters of Weibull model, equilibrium quality parameter $\left(X_{e}\right)$, and respective coefficient of determination, for weight loss, firmness and browning index, at different temperatures.

\begin{tabular}{lrrlrl}
\hline Quality parameters & $\mathrm{T}\left({ }^{\circ} \mathrm{C}\right)$ & $\alpha\left(\mathrm{d}^{-1}\right)$ & \multicolumn{1}{l}{$\beta$} & \multicolumn{1}{l}{$X_{e}$} & \multicolumn{1}{l}{$R^{2}$} \\
\hline Weight loss (\%) & 0 & 11.87 & 1.05 & 13.12 & 0.997 \\
& 5 & 17.51 & 1.02 & 13.19 & 0.997 \\
& 10 & 7.80 & 1.07 & 10.79 & 0.999 \\
Firmness (N) & 15 & 6.71 & 1.23 & 15.78 & 0.999 \\
& 0 & 7.62 & 0.43 & 87.85 & 0.754 \\
& 5 & 4.53 & 1.41 & 46.19 & 0.980 \\
& 10 & 1.98 & 1.07 & 40.92 & 0.989 \\
Browning index & 15 & 1.44 & 0.78 & 36.15 & 0.987 \\
& 0 & 97.28 & 0.24 & 23.94 & 0.864 \\
& 5 & 94.68 & 0.79 & 87.36 & 0.904 \\
& 10 & 117.19 & 0.89 & 220.55 & 0.991 \\
& 15 & 349.71 & 1.08 & 1906.10 & 0.983 \\
\hline
\end{tabular}

Table 3

Frequency factors, activation energy and coefficient of determination for scale $(\alpha)$ and shape $(\beta)$ parameters of Weibull model for weight loss and firmness.

\begin{tabular}{lllllll}
\hline Quality parameters & $\alpha_{0}\left(\mathrm{~d}^{-1}\right)$ & $\begin{array}{l}E_{a \alpha} \\
\left(\mathrm{kJ} \mathrm{mol}^{-1}\right)\end{array}$ & $R^{2}$ & $\beta_{0}$ & $\begin{array}{l}E_{a \beta} \\
\left(\mathrm{kJ} \mathrm{mol}^{-1}\right)\end{array}$ & $R^{2}$ \\
\hline Weight loss (\%) & 9.66 & 64.17 & 0.872 & 1.11 & 12.51 & 0.933 \\
Firmness (N) & 2.33 & 76.38 & 0.942 & 1.05 & 39.21 & 0.997 \\
\hline
\end{tabular}

\section{$F=T+325.32$}

Substituting the parameters, $\alpha, \beta$, and $X_{e}$, into Eqs. (4) and (5) in Eq. (3), the overall Weibull model was obtained for firmness, $F$ (Eq. (6)), which predicts firmness of sliced mushrooms as a function of time and temperature.

$$
F-[T+325.32]
$$

$\overline{141.14-[T+325.32]}$

$$
=\exp \left(-\left[\frac{t}{2.33 \times \exp \left(-\frac{76.4}{R_{c}}\left[\frac{1}{T}-\frac{1}{T_{\text {ref }}}\right]\right)}\right]^{1.05 \times \exp \left(-\frac{39.2}{R_{C}}\left[\frac{1}{T}-\frac{1}{T_{\text {ref }}}\right]\right)}\right)
$$

The fitting of Weibull model to the firmness data, as a function of time and temperature is shown in Fig. 4. Coefficients of determination of 0.956 (all data) and 0.979 (excluding data at $0{ }^{\circ} \mathrm{C}$ ) showed

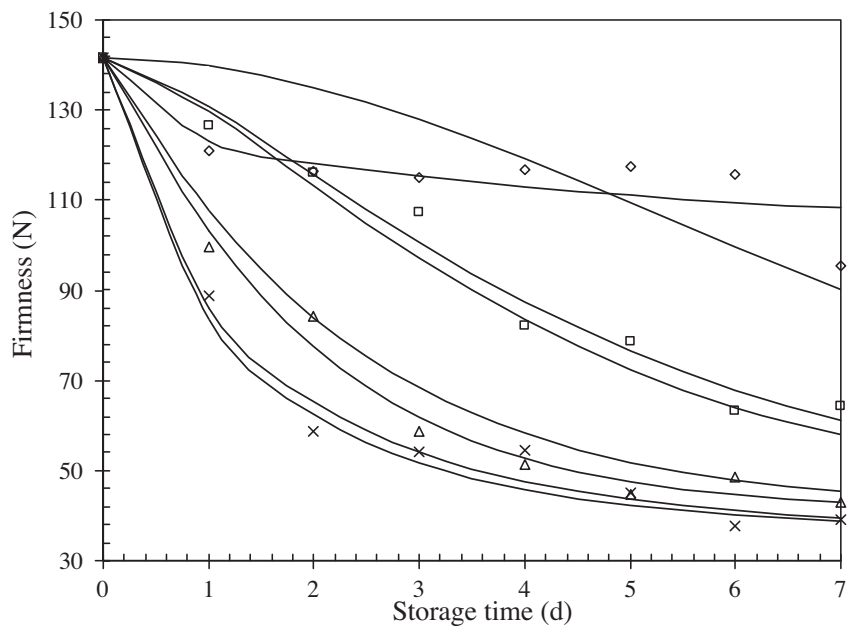

Fig. 4. Fitting of Weibull model to firmness data. Experimental data are represented by symbols at different temperatures $\left(0{ }^{\circ} \mathrm{C}(\diamond) ; 5{ }^{\circ} \mathrm{C}(\square) ; 10{ }^{\circ} \mathrm{C}(\triangle) ; 15^{\circ} \mathrm{C}(\times)\right)$. Weibull model as a function of time is represented by lines (-). The overall Weibull model, as a function of time and temperature, is represented by dotted lines (--).

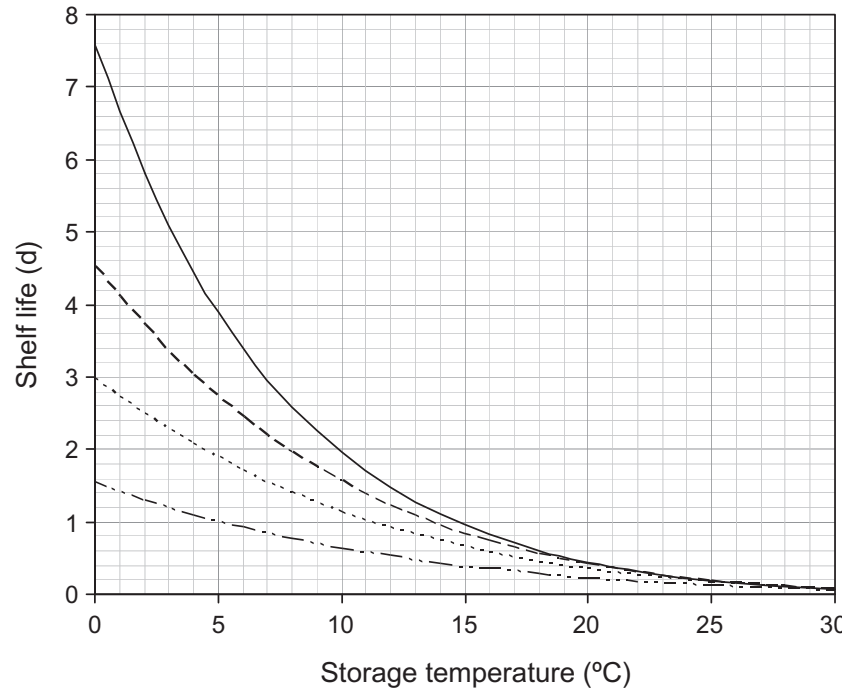

Fig. 5. Predicted shelf-life of sliced mushrooms, based on firmness, at different storage temperatures $-1 F_{0},---0.9 F_{0},----0.8 F_{0}$ and $----0.7 F_{0}$.

that Weibull model was appropriate to describe firmness changes with time and temperature, in spite of data obtained at $0{ }^{\circ} \mathrm{C}$ presented some deviation for $\beta$ value (Table 2 ). Therefore, shelf-life of sliced mushrooms was predicted as a function of storage temperature on the basis of firmness (Eq. (6)).

A limit of acceptance of 1 day at $15{ }^{\circ} \mathrm{C}$ was established for sliced mushrooms based on sensory overall appearance and firmness (data not shown) and these findings are in agreement with Mohapatra et al. (2011), who presented 0.7-1.0 as levels of sensory overall acceptability for mushrooms for 1 day at $15^{\circ} \mathrm{C}$. Sliced mushrooms lost firmness from 141.4 to $88.7 \mathrm{~N}$ after 1 day at $15{ }^{\circ} \mathrm{C}$, representing a loss of $40 \%$ of firmness. Thus, a limit of acceptance of firmness loss of $60 \%$ of the initial value was considered.

Shelf-life was obtained by difference of the time which led to reduce the initial firmness to 0.6 and the time which led to reduce to $1,0.9,0.8$, until 0.7 of the initial firmness at different temperatures. The shelf-life of sliced mushrooms based on its firmness, as a function of temperature, under optimum MAP conditions ( 1 perforation (58 perforations per $\mathrm{m}^{2}$ ) at $0{ }^{\circ} \mathrm{C}, 1\left(58\right.$ perforations per $\left.\mathrm{m}^{2}\right)$ at $5{ }^{\circ} \mathrm{C}, 3$ (174 perforations per $\mathrm{m}^{2}$ ) at $10^{\circ} \mathrm{C}$ and $6\left(349\right.$ perforations per $\mathrm{m}^{2}$ ) at $15^{\circ} \mathrm{C}$ ), packed in a tray covered with cellophane ${ }^{\mathrm{TM}} 335$ PS film is shown in Fig. 5. Fresh sliced mushrooms with $100 \%$ of initial firmness i.e. $1 F_{0}$ have 1 day of shelf-life at $15^{\circ} \mathrm{C}, 2$ days at $10^{\circ} \mathrm{C}$, 4 days at $5{ }^{\circ} \mathrm{C}$ and 7.5 days at $0{ }^{\circ} \mathrm{C}$. For sliced mushrooms with $80 \%$ of initial firmness i.e. $0.8 F_{0}$, the remaining shelf-life was half day at $15^{\circ} \mathrm{C}$, 1 day at $10^{\circ} \mathrm{C}, 2$ days at $5^{\circ} \mathrm{C}$ and 3 days at $0{ }^{\circ} \mathrm{C}$.

Sliced mushrooms lost firmness with time and temperature, therefore measuring the firmness at a specific time, and knowing the initial firmness of sliced mushrooms, it is possible to determine the remaining shelf-life. Thus, the model developed could be used to predict shelf-life of sliced mushrooms at any combination of time and temperature. These results also showed the importance of storage of sliced mushrooms at lower temperatures in order to minimise browning and weight loss. Thus, to extend the shelf-life of fresh sliced mushrooms it is important to maintain a storage temperature between 0 and $5{ }^{\circ} \mathrm{C}$, resulting in 7.5 to 4 days of shelf-life, respectively.

\section{Conclusions}

Increasing the storage temperature required an increase in the number of film perforations in order to obtain the optimum MAP 
conditions. At least one perforation was needed in order to avoid null $\mathrm{O}_{2}$ concentration that might lead to anaerobic respiration and potential resulting in growth of pathogens. Firmness was the most significant quality parameter affected by time and temperature, and this was used to develop a shelf-life kinetic model for sliced mushrooms. The shelf-life of fresh sliced mushrooms in an optimum package was found to be 7.5 and 4 days when stored at 0 and $5^{\circ} \mathrm{C}$, respectively.

\section{Acknowledgements}

The first author acknowledge financial support from the Erasmus Programme (2009) and research funding was provided under the NDP, through FIRM (08/R\&D-UL/661), administered by the Department of Agriculture, Fisheries \& Food, Ireland. Authors would also like to acknowledge Innovia Films Ltd. (UK) for supplying the packaging materials.

\section{References}

Antmann, G., Ares, G., Lema, P., Lareo, C., 2008. Influence of modified atmosphere packaging on sensory quality of shiitake mushrooms. Postharvest Biology and Technology 49, 164-170.

Ares, G., Parentelli, C., Gámbaro, A., Lareo, C., Lema, P., 2006. Sensory shelf life of shiitake mushrooms stored under passive modified atmosphere. Postharvest Biology and Technology 41, 191-197.

Barrerio, J.A., Milano, M., Sandoval, A.J., 1997. Kinetics of color change of double concentrated tomato paste during thermal treatment. Journal of Food Engineering 33, 359-371.

Chakrabarty, T., Giri, B.C., Chaudhuri, K.S., 1998. An EOQ model for items with Weibull distribution deterioration, shortages and trended demand: an extension of Fhiliṕs model. Computers Operations Research 25, 649-657.

Corzo, O., Bracho, N., Pereira, A., Vásquez, A., 2008. Weibull distribution for modeling air drying of coroba slices. Food Science and Technology 41, 20232028.

Cunha, L.M., Oliveira, F.A.R., Oliveira, J.C., 1998. Optimal experimental design for estimating the kinetic parameters of processes described by the Weibul probability density function. Journal of Food Engineering 37 (2), 175-191.

Escriche, I., Serra, J.A., Gómez, M., Galotto, M.J., 2001. Effect of ozone treatment and storage temperature on physicochemical properties of mushrooms. Food Science and Technology International 7, 251.

Gonzalez, J., Ferrer, A., Oria, R., Salvador, M.L., 2008. Determination of $\mathrm{O}_{2}$ and $\mathrm{CO}_{2}$ transmission rates through microperforated films for modified atmosphere packaging of fresh fruits and vegetables. Journal of Food Engineering 86, 194201.

Gormley, T.R., 1975. Chill storage of mushrooms. Journal of Science and Food Agriculture 26, 401-411.

Heard, G. M. (2002). Microbiology of fresh-cut produce. In O. Lamikanra, Fresh-Cut Fruits and Vegetables: Science, Technology, and Market (pp. 187-248). CRC Press.

Iqbal, T., Rodrigues, F.A., Mahajan, P.V., Kerry, J.P., 2009. Effect of time, temperature, and slicing on respiration rate of mushrooms. Journal of Food Science 74, 298303.

Kim, K.M., Ko, J.A., Lee, J.S., Park, H.J., Hanna, M.A., 2006. Effect of modified atmosphere packaging on the shelf life of coated, whole and sliced mushrooms. LWT 39, 364-371.

Mahajan, P.V., Oliveira, F.A.R., Macedo, I., 2008. Effect of temperature and humidity on the transpiration rate of the whole mushrooms. Journal of Food Engineering $84,281-288$
Mahajan, P. V., Oliveira, F. A. R., Sousa, M. J., Fonseca, S. C., Cunha, L. M. (2006). An interactive design of MA-packaging for fresh produce. In Handbook of Food Science, Technology, and Engineering (Vol. 3, pp. 1-7).

Mahajan, P.V., Oliveira, F.A.R., Montañez, J.C., Frias, J., 2007. Development of userfriendly software for design of modified atmosphere packaging for fresh and fresh-cut produce. Innovative Food Science and Emerging Technologies 8, 8492.

Mahajan, P.V., Sousa-Gallagher, M.J., Yuan, B., Patel, H.A., Oliveira, J.C., 2009. Development of web-based software for modified atmosphere packaging design, Controlled and Modified Atmosphere Packaging (CAMA2009), oral presentation, 4-7 April. Antalya, Turkey.

Maskan, M., 2001. Kinetics of colour change of kiwifruits during hot air and microwave drying. Journal of Food Engineering 48, 169-175.

Masson, Y., Ainsworth, P., Fuller, D., Bozkurt, H., 2002. Growth of Pseudomonas fluorencens and Candida sake in homogeneized mushrooms under modified atmosphere. Journal of Food Engineering 54, 125-131.

Montanez, J.C., Rodríguez, F.A.S., Mahajan, P.V., Frías, J.M., 2010. Modeling the gas exchange rate in perforation-mediated modified atmosphere packaging: effect of the external air movement and tube dimensions. Journal of Food Engineering 97, 79-86.

Mohapatra, D., Frias, J.M., Oliveira, F.A.R., Bira, Z.M., Kerry, J., 2008. Development and validation of a model to predict enzymatic activity during storage of cultivated mushrooms (Agaricus bisporus spp.). Journal of Food Engineering 86 (1), 39-48.

Mohapatra, D., Bira, Z.M., Kerry, J.P., Frias, J.M., Rodrigues, F.A., 2010. Postharvest hardness and colour evolution of white button mushrooms (Agaricus bisporus). Journal of Food Science 75 (3), E146-E152.

Mohapatra, D., Bira, Z.M., Frias, J.M., Kerry, J.P., Rodrigues, F.A., 2011. Probabilistic shelf life assessment of white button mushrooms through sensorial properties analysis. Food Science and Technology 44, 1443-1448.

Nichols, R., Hammond, J.B.W., 1973. Storage of mushrooms in pre-packs: The effect of changes in carbon dioxide and oxygen on quality. Journal of the Science of Food and Agriculture 24, 1371-1381.

Odriozola-Serrano, I., Soliva-Fortuny, R., Martín-Belloso, O., 2009. Influence of storage temperature on the kinetics of the changes in anthocyanins, vitamin $C$ and antioxidant capacity in fresh-cut strawberries stored under high oxygen atmospheres. Journal of Food Science 74, 184-191.

Oms-Oliu, G., Odriozola-Serrano, I., Soliva-Fortuny, R., Martín-Belloso, O., 2009. Use of Weibull distribution for describing kinetics of antioxidant potential changes in fresh-cut watermelon. Journal of Food Engineering 95, 99-105.

Oliveira, F., Sousa-Gallagher, M.J., Mahajan, P.V., Teixeira, J.A., 2012. Evaluation of MAP engineering design parameters on quality of fresh sliced mushrooms, $J$. Food Engineering 108, 507-514.

Parentelli, C., Ares, G., Corona, M., Lareo, C., Gámbaro, A., Soubes, M., Lema, P., 2007. Sensory and microbiological quality of shiitake mushrooms in modifiedatmosphere packages. Journal of the Science of Food and Agriculture 87, $1645-1652$.

Sanz, C., Perez, A.G., Olias, R., Olias, J.M., 2000. Modified atmosphere packaging of strawberry fruit: Effect of package perforation on oxygen and carbon dioxide. Food Science and Technology International 6, 33-38.

Simon, A., Gonzalez-Fandos, E., Tobar, V., 2005. The sensory and microbial quality of fresh sliced mushrooms (Agaricus bisporus L.) packaged in modified atmospheres. International Journal of Food and Sci and Tech. 40, 943-952.

Robertson, G. L. (2006a). Packaging of horticultural products. In Food Packaging: Principles and Practice (pp. 360-380). CRC Press.

Robertson, G.L., 2006. Shelf Life of Foods. Principles and Practice. CRC Press, In Food Packaging.

Roy, S., Anantheswaran, R.C., Beelman, R.B., 1996. Modified atmosphere and modified humidity packaging of fresh mushrooms. Journal of Food Science 61 (2), 391-397.

Varoquaux, P., Gouble, B., Barron, C., Yildiz, F., 1999. Respiratory parameters and sugar catabolism of mushroom (Agaricus bisporus L.). Posharvest Biology and Technology 16, 51-61.

Zivanovic, S., Buescher, R., Kim, S.K., 2003. Mushroom texture, cell wall composition, colour and ultrastructure as affected by $\mathrm{pH}$ and temperature. Journal of Food Science 68, 1860-1865. 